\title{
Introducción histórica y canónica al oficio eclesiástico
}

\author{
Historical and Canonical Introduction \\ to the Ecclesiastical Office
}

\section{Antonio VIANA}

Profesor Ordinario de Organización Eclesiástica

Universidad de Navarra. Facultad de Derecho Canónico. Pamplona

orcid 0000-0002-9857-1500

aviana@unav.es

Resumen: El artículo estudia los precedentes históricos del oficio eclesiástico, una figura prevista por las normas generales del ordenamiento canónico. Se presentan aquí las referencias al oficio en el derecho romano y en las principales fuentes del derecho canónico medieval. En la segunda parte del estudio son examinados tres aspectos que configuran el contenido de la noción de oficio en su evolución histórica; a saber: su vinculación con la potestad eclesiástica, su alcance y significado institucional, más allá de la sucesión de personas individuales, y finalmente su relación histórica e interdependiente con la institución del beneficio eclesiástico.

Palabras clave: Oficio, Beneficio, Persona jurídica.
Abstract: The article explores the historical background to the ecclesiastical office, a figure defined within the general norms of the canonical order. References to the office in Roman law and in the main sources of medieval canon law are presented here. The second part of the article examines three aspects that shape the content of the idea of the office over the course of its historical development, namely: its links to ecclesiastical power; its scope and institutional significance, beyond the succession of specific individuals; and finally, its historical and interdependent relationship with the institution of ecclesiastical benefit.

Keywords: Office, Benefit, Legal Person. 
E n estas páginas se presenta una síntesis histórica de la figura del oficio eclesiástico, como introducción al estudio de esa institución, que figura entre las normas generales de la codificación canónica del siglo $\mathrm{XX}^{1}$. Tras unas breves anotaciones sobre la etimología de la palabra latina officium, recordaré la pluralidad de significados del término, que es empleado en el lenguaje civil y eclesiástico. El uso secular de la palabra se refiere ante todo a su original sentido de deber cívico y moral, pero también incluye un significado propio en el lenguaje jurídico administrativo, por ejemplo en el derecho público italiano (donde se distingue a veces entre ufficio y órgano ${ }^{2}$ ). Ya en el lenguaje eclesiástico, officium comprende un uso litúrgico y también un preciso significado jurídico canónico, que es el que nos interesa particularmente.

Tras esta primera aproximación al contenido del término, partiendo de los antecedentes romanos de officium, intentaré presentar una breve síntesis de su alcance en las fuentes principales del derecho canónico clásico.

Por fin, el estudio examinará tres aspectos que configuran el contenido de la noción de oficio según su evolución histórica; a saber: su vinculación con la potestad eclesiástica, su alcance y significado institucional, más allá de la sucesión de personas individuales, y finalmente su relación histórica e interdependiente con la institución del beneficio eclesiástico.

\section{OFFICIUM ENTRE MORAL, LITURGIA Y DERECHO}

Tanto la palabra latina officium como el verbo officio tienen la misma raíz, de $o b$ y facio. El verbo officio significa oponer, impedir, obstaculizar, pero también incluye el sentido positivo de salir al encuentro de alguien o algo como auxilio o ayuda: «facere se obviam alicui rei vel personae tam auxiliandi et obsequendi, quam impediendi et obsistendi causa». Por su parte, el sustantivo officium no deriva del verbo officio en el sentido negativo apuntado (oponer, impedir), sino más bien en el sentido positivo de ayuda o auxilio. Según otra opinión, el sustantivo officium podría derivar también de opificina: en paralelo a la procedencia con síncopa de officina a partir de opificina, así también officium de opificium ${ }^{3}$.

${ }^{1}$ Cfr. cc. 145 del CIC de 1917, $145 \$ 1$ del CIC de 1983 y $936 \$ 1$ del CCEO.

${ }^{2}$ Cfr. M. S. GIANNINI, Istituzioni di diritto amministrativo (a cura di A. Mirabelli Centurione), $2^{\mathrm{a}}$ ed., Giuffrè, Milano 2000, 13-16.

3 Cfr. E. ForCELlin, Lexicon totius latinitatis, reimpr., Patavii 1864-1926, III, Bononiae 1965, 477 y 478 . 
De manera general officium alude a una prestación que debe darse o una tarea por realizar, de acuerdo con las circunstancias personales, locales y temporales. Este sentido general de officium comporta un cierto contenido de obligación o responsabilidad personal. Una tarea que debe ser atendida y desempeñada como corresponde ${ }^{4}$. Además, el término latino ha tenido distintas aplicaciones, hasta designar en concreto al titular del cargo, el oficial ${ }^{5}$.

En las principales lenguas modernas permanecen las palabras equivalentes de oficio, ufficio, office -en francés y en inglés-, con las peculiaridades del término $A m t$, en alemán, que en el ámbito eclesiástico tiene un sentido no sólo jurídico, sino también teológico, referido al sacramento del orden sagrado en sus diversos ordines o grados, tal como son previstos por ejemplo en el c. $1009 \$ 1$ del CIC de $1983^{6}$. En español, oficio mantiene entre sus significados la referencia a funciones eclesiásticas de carácter litúrgico y, sobre todo, expresa la ocupación habitual, un cargo o ministerio, una profesión de algún arte mecánica, y también sencillamente la función propia de alguna $\operatorname{cosa}^{7}$.

El uso del término oficio en la vida de la Iglesia bascula entre los significados moral, litúrgico y canónico, según el contexto en el que se emplea. El sentido moral de oficio como deber y virtud está presente en la literatura clásica, como se comprueba elocuentemente a partir sobre todo de la obra $D e$ officiis de Cicerón. Escrita en el año 44 a.C., equivale a un tratado de ética aplicada, en el que se refieren contenidos y exigencias especiales de la moral pública, pensados sobre todo para la clase dirigente romana.

En la literatura cristiana existe una tradición de obras que siguen este esquema moral, entre las que sobresale el De officiis (ministrorum, se añadiría más tarde) de san Ambrosio (ca. 388-389), que es un tratado sobre las virtudes humanas y sobrenaturales del bautizado y viene a suponer un desarrollo ya cristiano del pensamiento ciceroniano, con una importante influencia en la literatura posterior ${ }^{8}$.

\footnotetext{
${ }^{4}$ Ibid., 478. Cfr. también D. Du CANGE, Glossarium mediae et infimae latinitatis, VI, $2^{\mathrm{a}}$ ed., Paris 1938, 635; A. ERnOuT - A. MeILlet, Dictionnaire etymologique de la langue latine. Histoire des mots, $3^{\text {a }}$ ed., Paris 1951, 815.

${ }^{5}$ Cfr. E. ForCELlinI, Lexicon totius latinitatis, 478-479.

${ }^{6}$ Cfr. E. M. MoreIn, Officium ecclesiasticum et universitas personarum. Bestimmung des Rechsinstituts «Amt», LIT, Berlin 2006, 7-8.

7 Cfr. Diccionario de la lengua española, actualización de 2017, en www.dle.rae.es.

${ }^{8}$ Cfr. Ambrosio de Mitán, Los deberes, Introducción, traducción y notas de D. Ramos-Lissón, Ciudad Nueva, Madrid 2015, 8-11 de la Introducción.
} 
Más tarde, a caballo entre los siglos VI y VII, san Isidoro de Sevilla usa el término oficio no tanto en el sentido de tarea o encargo, sino aplicado a la organización de la sagrada liturgia. Por una parte debe destacarse el libro VI de las Etimologías, obra compuesta en torno al año 615, que está dedicado a los «libros y oficios eclesiásticos» ${ }^{9}$. Por oficio entiende aquí san Isidoro las tareas que atañen a las cosas sagradas y divinas; por eso trata de la liturgia de las horas, la misa, el coro, y en general la terminología aplicada a la acción litúrgi$\mathrm{ca}^{10}$. Por otra parte, el obispo de Sevilla es autor de una obra De ecclesiasticis officiis, compuesta entre el 610 y el 615, que es un pequeño tratado de la organización del culto divino y la liturgia española antigua, en el que abunda en la perspectiva del libro VI de las Etimologías ${ }^{11}$.

Este uso del término oficio referido a la acción litúrgica se mantiene, desde luego, en el lenguaje eclesiástico y da nombre señaladamente a la liturgia de las horas, el officium divinum, y otras acciones sagradas. Por su parte, la inspiración de oficio en sentido moral nunca dejará de estar presente en el derecho canónico, a causa del sentido ministerial de la potestad eclesiástica, que principalmente se ejerce a través del oficio entendido como cargo. Un cargo que en realidad se asume como un servicio a la comunidad.

En efecto, como explicó Yves Marie Congar, la convicción de que la función de la jerarquía eclesiástica es un servicio a los fieles «recorre por completo la trayectoria de la tradición cristiana» y configura desde los comienzos del cristianismo todo un lenguaje eclesiológico y jurídico sobre la base del Nuevo Testamento ${ }^{12}$. Esta concepción de la jerarquía eclesiástica como un ministerio que se ejerce en la Iglesia para ayuda de los hermanos, a imitación de Jesucristo y siempre en su nombre, expresa el contenido dinámico de la potestad. Toda potestad en la Iglesia es un servicio, y ningún oficio o munus mediante el que se ejerza establemente esa potestad puede dejar de participar de esa orientación fundamental en el planteamiento y

9 Cfr. M. Díaz y Díaz, Introducción general, en SAN Isidoro de SeviLla, Etimologías, ed. bilingüe, vol. I, BAC, Madrid 1982, 615.

10 «Officiorum plurima genera esse, sed praecipuum illud quod in sacris divinisque rebus habetur»: VI.19.1 (p. 608, de la ed. cit.; cfr. también, 609-623).

${ }^{11}$ He consultado la ed. del Corpus Christianorum, series latina, 113, Brepols, Turnholti, a cargo de Ch. M. LAWSON.

12 Cfr. Y. M. Congar, La ferarquía como servicio según el Nuevo testamento y los documentos de la Tradición, en Y. M. CONGAR - B. D. DupuY (eds.), El episcopado y la Iglesia universal, trad. esp. del original francés de 1964, Barcelona 1966, 67; cfr. IDEM, Algunas expresiones tradicionales del servicio cristiano, ibid., 97-126. 
ejercicio de sus actividades. Esta consideración ministerial no sólo es de orden moral, sino que está llena también de consecuencias de orden jurídico en cuestiones que afectan al contenido del principio de subsidiariedad, los controles y procedimientos en el ejercicio de la potestad administrativa, la conexión entre legalidad y flexibilidad de la ley, la protección de la autonomía de las asociaciones y la adecuada tutela jurídica de los fieles ${ }^{13}$. Es notable en este sentido el texto de san Agustín De civitate Dei, libro XIX, c. 19, recogido por Graciano: Qui preesse non prodesse desiderat non debet episcopari: no debe ser obispo quien sólo desee presidir, pero no servir ${ }^{14}$. Y en el contenido del capítulo se dice: «Exponere uoluit quid sit episcopatus, quia nomen est operis, non honori».

\section{DERECHO ROMANO}

A partir del sentido moral de oficio, el derecho romano desarrolla un significado referido al cuidado del bien ajeno, público y privado, a través de cargos como el de juez, cónsul o pretor. En las fuentes jurídicas romanas se encontrará un concepto de oficio como conjunto de atribuciones encomendadas a una persona con potestad.

A falta de una noción abstracta y general, el derecho público romano usa un lenguaje referido a distintas funciones agrupadas en torno a términos como dignitas, honor, magistratus (en sentido genérico), pero también munus y officium, como sucederá también en el derecho canónico ${ }^{15}$. En este contexto el término munus puede significar un don, una carga o un deber, como por ejemplo en el título del Digesto dedicado a la significación de las palabras, donde se lee que munus significa un regalo que se da, una carga que se perdona y también un oficio-deber, como es el caso de algunos militares ${ }^{16}$.

13 Remito aquí a los estudios publicados en la obra colectiva, La dimensión de servicio en el gobierno de la Iglesia (A. Viana, ed.), Navarra Gráfica Ediciones, Pamplona 1999.

${ }^{14}$ Cfr. C.8 q.1 c.11 (ed. Friedberg I, col. 593).

${ }^{15}$ En torno al uso de estos términos en las fuentes del derecho romano, cfr. E. QUINTANA-ORIVE, «Officium, munus, honor...»: precedentes romanos del término «funcionario» y de otras categorías jurídico-administrativas, Revista digital de Derecho Administrativo 16 (2016) 263-278 (http://dx.doi.org/10.18601/21452946.n16.12).

${ }^{16}$ D.50.16.18 (Paulus, 9 ad edictum): «"Munus" tribus modis dicitur: uno donum, et inde munera dici dari mittive; altero onus, quod cum remittatur, vacationem militiae munerisque praestat, inde immunitatem appellari; tertio officium, unde munera militaria, et quosdam milites munificos vocari. Igitur municipes dici, quod munera civilia capiant». 
Encontramos también en las fuentes romanas la expresión munus publicum, tan característica del significado propio del oficio en el derecho canónico. La función o tarea pública es desempeñada por magistrados y titulares de oficios, pero también por ciudadanos a quienes el magistrado impone el deber de contribuir al bien y a la utilidad de todos ${ }^{17}$.

El término officium es frecuentemente utilizado en las fuentes jurídicas de los distintos periodos del imperio. En la redacción de las rúbricas del Código de Teodosio (a. 438) tuvieron influencia los llamados "libros de officio" de la jurisprudencia de los siglos II y III. En un primer momento estos escritos describen sobre todo la situación de los ciudadanos ante la administración de justicia o la organización financiera, pero más tarde son redactados para tratar de las funciones de los oficiales, lo que dará lugar a la elaboración de un concepto de oficio como cargo público. Este significado se encuentra en los títulos 5 a 22 del Código teodosiano; y las compilaciones de Justiniano, tanto el Codex (a. 533) como el Digesto (a. 534), mantienen este sentido jurídico público de oficio ${ }^{18}$.

El Digesto menciona muchas obras de este estilo (libros de officio), a cargo de famosos juristas con autoridad ${ }^{19}$. Los mismos títulos del libro I del Digesto están dedicados a los distintos oficios, como De officio consulis, praefecti praetorio, praefecti Urbi, quaestoris, praetorum, praefecti vigilum, proconsulis et legati, augustalis, praesidis, procuratoris Caesaris, iuridici, assessorum ${ }^{20}$. Por lo tanto, además del sentido de deber u obligación moral, officium indica en los textos jurídicos, a partir del principado (periodo que coincide precisamente con los dos primeros siglos del cristianismo), un contenido que será conservado en la historia; es decir, el conjunto de responsabilidades y deberes que corresponden a un cargo público ${ }^{21}$.

${ }^{17}$ D.50.16.239.3: «"Munus publicum" est, officium privati hominis, ex quo commodum ad singulos universosque cives, remque eorum imperio magistratus extraordinarium pervenit».

${ }^{18}$ Cfr. B. BasDevant-Gaudemet, Office ecclésiastique. Repères pour une bistoire d'un concept, en EADEM, Église et Autoritès. Etudes d'bistoire de droit canonique médiéval, Presses universitaires de Limoges, Limoges 2006, 274-275.

19 Cfr. E. QUINTANA-OrIvE, «Officium, munus, honor», 269 y nota 28.

${ }^{20}$ Cfr. D.1.10-22.

${ }^{21}$ Cfr. E. QuinTANA-OrIve, «Officium, munus, honor», 268, que da los siguientes textos del Digesto: D.1.11.1. (Arc. Char., de off. praef. praet.): «Breviter commemorare necesse est, unde constituendi praefectorum praetorio officii origo manaverit»; D.1.18.12. (Proc., 4 epist.): «Sed licet is, qui provinciae praeest, omnium Romae magistratuum vice et officio fungi debeat...»; D.1.22.1. (Paul., de off. ads.): «Omne officium adsessoriis, quo iuris studiosi partibus suis funguntur, in his fere causis constat: in cognitionibus postulationibus libellis edictis decretis epistulis». 
Officium significa también en diversos lugares del Código Teodosiano, las Novelas posteriores y el Código de Justiniano el grupo de empleados que forman parte de la oficina colaboradora de un magistrado superior ${ }^{22}$.

Como resumen de esta aproximación, podemos decir con BasdevantGaudemet que el derecho romano va más allá de la noción moral y ofrece un concepto de oficio referido ordinariamente a los cargos públicos; y esto en la época del bajo imperio, que coincidió con los primeros pasos de la Iglesia antigua, cuando ésta se iba dotando de su propia administración ${ }^{23}$.

\section{El OFICIO EN LAS PRINCIPALES FUENTES CANÓNICAS MEDIEVALES}

La Iglesia católica bebe en las fuentes de la tradición jurídica romana en tantas de sus instituciones y entre ellas la del oficio. Esta figura se adapta bien a las exigencias de la actividad jurídica y pastoral de la Iglesia, porque asegura una organización estable de las tareas de evangelización y gobierno. Además, es un buen instrumento jurídico para adecuarse a las necesidades de extensión y universalidad del mensaje evangélico, con centros o unidades que actúan públicamente en los diversos lugares y países. Permite, al mismo tiempo, distribuir las responsabilidades de acuerdo con un sistema de relaciones entre los titulares de los cargos, subordinados unos a otros o bien coordinados entre sí.

En este apartado, más que detenerme en la opinión de decretistas y decretalistas consideraré directamente el tratamiento del oficio en las fuentes normativas. El término officium se encuentra frecuentemente en todas las colecciones canónicas medievales y es utilizado 567 veces en el Decreto de Graciano $^{24}$.

${ }^{22}$ Cfr. C. Th. 1.5.13: «decernimus, ut, si quis palatinus ex officio viri illustris comitis sacrarum largitionum per provincias repertus fuerit...»; C. Th. 1.15.5: «Officium vicariae per Africam praefecturae intra eum numerum colligatur, ut trecentos minime possit excedere...»; Nov. Val. 22 pr.: «officium sedis celsitudinis tuae, sine quo necessitates publicae nequeunt expediri, per infortunia multa iam saucium medicinam nostrae curationes exposcit...»; C. J. 1.30.3: «officio quoque rectoris provinciae (...) trium librarum auri dispendio feriendo». Vid. E. Quintana-OrIVE, «Officium, munus, honor», 268.

23 «Ayant peut-être hérité de Ciceron, mais ayant pris des distances par rapport à la doctrine cicéronniene, le droi roman maniait couramment le concept d'office pour désigner les charges publiques, à cette époque du Bas-Empire qui était celle où l'Église, desormais reconnue et même favorisée par l'État, se dotait de sa propre administration»: B. BASDEVANT-GAUDEMET, Office ecclésiastique, 275.

${ }^{24}$ Cfr. B. Basdevant-Gaudemet, Office ecclésiastique, 276. 


\subsection{En el Decreto de Graciano}

El Decreto de Graciano usa ampliamente officium (offitium) según diversos sentidos del término que no son contradictorios entre sí, pues guardan relación unos con otros. Además del sentido moral que connota el término desde la tradición romana y cristiana (los deberes que a cada uno corresponden en la comunidad y las virtudes que está llamado a vivir), se pueden distinguir: a) un sentido genérico y b) otro específico.

a) El sentido genérico de officium en el Decreto se manifiesta ante todo en grupos de textos que se aplican a los distintos grados del ministerio sagrado y concretamente a los obispos, presbíteros y diáconos, titulares de un clericalis offitium ${ }^{25}$. En este sentido, encontramos numerosas referencias al oficio en el ámbito pastoral y sobre todo litúrgico, aspecto este último muy presente en la causa 16 de la segunda parte del Decreto, donde son abundantes los términos clericorum offitia, sacerdotalis offitium, offitium presbiteri, ad clericatus offitium ${ }^{26}$. Es muy frecuente en Graciano el uso de officium como término genérico para referirse a cualquier tarea eclesiástica que corresponda a los clérigos ${ }^{27}$.

b) En segundo lugar, se descubre en el Decreto un sentido específico de oficio, no tan amplio como el que agrupa a los clérigos, pero siempre en relación con el orden sagrado. Son casos en los que los cargos vienen designados por su propio nombre diferenciador; a veces formando parte de una lista. Uno de los textos que debe destacarse en este sentido se encuentra en la primera parte del Decreto, D.25 c.1. En él se trata de la necesidad de examinar a los candidatos al orden sagrado. Graciano presenta una epístola falsamente atribuida a Isidoro de Sevilla que tuvo influencia en las colecciones canónicas a través de su recepción en las decretales pseudoisidorianas ${ }^{28}$. La carta contiene

${ }^{25}$ Es poco útil alegar textos en este apartado, porque son muy abundantes. Cfr. entre muchos, D.45 c.7; D.87 c.2; D.88 c.2; C.12 q.1 c.7.

${ }^{26}$ Cfr. C.16, especialmente q.1ss.: Utrum monachis offitia populis celebrare, penitentiam dare et baptizare? Cfr. también De cons. D. 1 cc. 7 y 21.

${ }^{27}$ Cfr., por ejemplo, D.38 c.1: «qui docendi offitium in populo susceperunt»; D.36 c.1: «quia litteris carens sacris non potest esse aptus offitiis»; D. 50 c.7: «Si episcopus, presbiter, aut diaconus capitale crimen commiserit (...) ab offitii honore depositus in monasterio detrudatur»; D.54 c.23: «ad quodlibet ecclesiasticum offitium provehatur»; D.32 c.13: «ab ecclesiastico removeantur offitio»; C.26 q.1 c.6: «quod enim ad alia offitia confertur»; D.50 c.69: «ad clericatus offitium non admitti»; D.55 c.9: «ad aliquod clericatus offitium».

${ }^{28}$ Cfr. P. LaNDAU, Die Ursprünge des Amtsbegriff im klassischen kanonischen Recht. Eine quellengeschichtliche Untersuchung zum Amtsrecht und zum Archidiakonat im Hochmittelalter, en IDEM, Offi- 
un elenco de lo que corresponde a los distintos oficios eclesiásticos, como explica el dictum posterior que la acompaña ${ }^{29}$. En efecto, la epístola comienza por el hostiarius y sigue por el exorcista, el acolitus, psalmista, lector, subdiaconus, diaconus, presbiterus hasta llegar al nivel superior del episcopus. Son, por tanto, los grados del sacramento del orden y diferentes ministerios litúrgicos. Pero además de la lista señalada, se menciona también en el texto pseudoisidoriano otro elenco paralelo en el que sobresale el oficio del archidiaconus, del que se declaran algunas funciones de autoridad y administración, también el archipresbiter-subordinado al obispo y al archidiácono, y al que corresponde la solicitud por otros presbíteros-, el primicerius y el thesaurarius. Algunas de las funciones de esta jerarquía secundaria son de administración de basílicas e iglesias y gestión de ofrendas, sobre todo en el caso del archidiácono.

De este modo, están apuntados en el texto que aquí recoge Graciano los ministerios litúrgicos que corresponden a los distintos cargos clericales y también algunas tareas auxiliares, asociadas al gobierno de los lugares sagrados. El sentido prevalente de oficio es aquí el de ministerio litúrgico según los distintos grados del sacramento del orden sagrado.

Los oficios especiales del archidiácono y arcipreste (archipresbiter) son mencionados con frecuencia en los textos del Decreto, pero también otros oficios concretos en las diócesis, como el vicedominus y el yconomus ${ }^{30}$. Encontramos también elencos de oficios en textos de la segunda parte del Decreto, algunos de contenido genérico, como en C.1 q.2 c. $3^{31}$ y otros más concretos ${ }^{32}$.

Finalmente, en esta aproximación a la noción de oficio en el Decreto de Graciano, resulta de interés mencionar, al menos esquemáticamente, algunas determinaciones contenidas en los textos que son relevantes para el tratamiento de aquella noción. Así, se encuentran distintas advertencias sobre la

cium und libertas christiana, Verlag der Bayerischen Akademie der Wissenschaften, München 1991, 9 (estudio también publicado en IDEM, Europäische Rechsgeschichte und kanonisches Recht im Mittelalter, Wissenschaflicher Verlag Bachmann, Badenweiler 2013, 341-384).

$29 \ll$ Ex hac epistola liquet quid cuiusque offitii sit»: d.p. D.25 c.1.

${ }^{30}$ Sobre estos últimos, cfr. D.89 cc.2 y 3.

31 «Si quis episcopus prebendas, archidiaconatus, preposituras uel aliqua ecclesiastica offitia uendiderit, uel aliter, quam statuta sanctorum Patrum precipiunt, ordinauerit, ab offitio suspendatur. Dignum est enim, ut, sicut gratis episcopatum accepit, ita membra eiusdem episcopatus gratis distribuat».

32 Así en C.1 q.3 c.8: «In nomine uero procuratoris intelligit prefata synodus quemlibet ecclesiasticarum rerum amministratorem, ut, uerbi gratia, prepositum, yconomum, uicedominum; defensoris nomine aduocatum siue castaldum, et iudicem; in subiecto regulae archipresbiterum, archidiaconum, canonicum, monachum uel quemlibet mancipatum ecclesiastico offitio». 
prohibición del favoritismo y la acepción de personas en la selección de los titulares de los oficios ${ }^{33}$; y reglas que prohíben la acumulación de dos oficios por una misma persona ${ }^{34}$. Pueden destacarse también algunas determinaciones que afirman lo que podría denominarse el significado público del oficio frente a concepciones iusprivatistas; por ejemplo, para contestar a reclamaciones basadas en un supuesto derecho hereditario sobre el oficio ${ }^{35}$. Además, la causa VIII de la segunda parte del Decreto incluye una serie de cuestiones que el propio Graciano se plantea; entre ellas, si puede un obispo instituir a su sucesor en el oficio: an liceat episcopo successorem sibi instituere? Después de alegar distintos textos contrarios a esta posibilidad, puesto que altera el derecho eclesiástico establecido, el propio Graciano concluye que la posibilidad de que un obispo elija a su sucesor en el oficio está prohibida. Esto no quiere decir que no pueda tratar el asunto con los demás obispos; lo que resulta prohibido es disponer por testamento de su oficio como si se tratara de una dignidad personal ${ }^{36}$.

Un tema mayor que puede mencionarse también es la distinción presente en Graciano entre potestas officii y executio potestatis. En algunos de sus dicta el maestro emplea esta distinción, que ha sido ampliamente estudiada a propósito de la evolución histórica de la distinción entre la potestad de orden y de jurisdicción ${ }^{37}$. De momento, me limito a mencionarla en cuanto que tiene que ver con la noción de oficio presente en el Decreto. Comentando a san Agustín, Graciano distingue, a propósito de la situación canónica de los herejes, entre la potestas offitii y el ejercicio de la potestad; la potestad del oficio no se pierde por la herejía ni por la suspensión, ya que está vinculada al orden sagrado ${ }^{38}$.

33 «Propinquis, uel etiam fauore sibi coniunctis, ecclesiastica offitia committere non audeat». d.p. D.89 c. 5 .

34 «Singula ecclesiastici iuris offitia singulis quibusque personis singillatim committi iubemus»: D.89 c.1; «In dispensatione uero ecclesiae hanc regulam obseruandam nouerit, ut nulli quantumlibet exercitatae personae duo simul offitia committat, neque secularibus uiris res ecclesiasticas gubernandas committat»: d.a. D.89 c.1.

35 C.8 q.1 c.7: «Apostolica auctoritate prohibemus, ne quis ecclesias et prebendas, preposituras, capellanias, aut aliqua ecclesiastica offitia hereditario iure ualeat uendicare aut expostulare presumat. Quod si quis inprobus aut ambitionis reus attemptare presumpserit, debita pena mulctabitur et postulatis carebit».

36 d.p. C.8 q.1 c.7: «His omnibus auctoritatibus prohibentur episcopi successores sibi instituere. Sed aliud est de sui successoris electione cum fratribus deliberare, et aliud est ex testamento tamquam suae dignitatis heredem sibi querere. Illud fieri permittitur: hoc autem penitus prohibetur».

37 Cfr. R. L. Benson, The bishop-elect. A study in medieval ecclesiastical office, Princeton University Press, Princeton NY 1968, 50-52.

38 Cfr. d.p. C.24 q.1 c.37; d.p. C.1 q.1 c.97; d.p. C.16 q.1 c.19; d.p. C.16 q.1 c.40. 
Finalmente, puede indicarse también que en distintos lugares del Decreto de Graciano el oficio como término genérico se usa en conexión con el beneficio: offitium et beneficium, una institución esta última diferente del oficio, pero estrechamente vinculada con él a lo largo de la historia ${ }^{39}$.

\subsection{Sistemática de las Decretales}

Un nuevo paso en la evolución legal del concepto de oficio lo constituyó el Liber Extra de Gregorio IX, que fue compuesto en 1234, un siglo después del Decreto de Graciano. El libro I de las decretales gregorianas refleja la evolución de la ciencia canónica, ya que en él se presenta un complejo normativo referido a la organización eclesiástica, donde se encuentran disposiciones relativas a la provisión y cesación en los oficios (postulación, elección, traslado, renuncia) ${ }^{40}$.

Después de algunos títulos relativos al orden sagrado (del 11 al 22), el libro I de las decretales gregorianas contiene otros títulos que no se distribuyen principalmente, como en Graciano, según las distintas funciones litúrgicas, sino que siguen el estilo de los clásicos libros de officio conocidos por la tradición romana, comenzando por el título dedicado al archidiácono. Concretamente ésta es la distribución del libro I después del título 22:

- De officio archidiaconi (tít. 23)

- De officio archipresbyteri (tít. 24)

- De officio primicerii (tít. 25)

- De officio sacristae (tít. 26)

- De officio custodis (tít. 27)

- De officio vicarii (tít. 28)

- De officio et potestate iudicis delegati (tít. 29)

- De officio legati (tít. 30)

- De officio iudicis ordinarii (tít. 31)

- De officio iudicis (tít. 32)

A causa de su contenido jurídico, al elenco anterior pueden añadirse los siguientes títulos:

${ }^{39}$ Cfr. D. 32 c. 10: «Eos, qui post diaconatum uxoribus uacare uoluerint, ab omni sacro ordine remouemus, offitio atque beneficio ecclesiae carere decreuimus»; d.p. C.1 q: «offitio autem uel beneficio ecclesiae priuari, spiritualis pena est».

${ }^{40}$ Cfr. X.1.5, X.1.6, X.1.7, X.1.8, X.1.9. 
- De procuratoribus (tít. 38)

- De syndico (tít. 39)

- De arbitris (tít. 43)

A diferencia del Decreto de Graciano, esta sistemática comporta una distinción respecto al sacramento del orden sagrado, puesto que presta atención sobre todo a las funciones de cada cargo, con independencia del grado sacramental que corresponda ${ }^{41}$. A estos efectos, el uso del término oficio comporta un elemento de organización que no se identifica sin más con las personas físicas.

Además, hay que notar que junto con el término officium, el Liber Extra emplea otras denominaciones genéricas para agrupar distintas funciones públicas, como pueden ser las de dignitas (X.1.7.1 y 2), ecclesia (ibid., referido a los oficios con cura de almas), ministerium (X.1.24.2); otras veces el término oficio es acompañado de un adjetivo que añade expresividad a la denominación del cargo, como en el caso de pastorale officium (X.1.9.10), o se vincula con el beneficio (officium et beneficium: X.1.9.7).

Otra precisión interesante es que officium designa el cargo, pero también la tarea: de predicación, de visita, de representación, de juicio. Así, el título De officio et potestate iudicis delegati trata propiamente de aspectos de la potestad delegada. Hoy entendemos la potestad delegada como una forma de misión canónica alternativa a la potestad ordinaria y, por lo tanto, independiente del oficio, por lo que suena contradictorio hablar de un oficio delegado ${ }^{42}$. Sin embargo, lo que contiene aquel título de las decretales son disposiciones sobre el ejercicio de la delegación, sin denominación específica de oficio alguno. En efecto, las decretales gregorianas tratan allí de típicas cuestiones jurídicas de las funciones delegadas, como son su interpretación, atribución a varias personas, la eficacia de la delegación hecha por la Santa Sede, la subdelegación y sus condiciones, la

41 «Die hier genannten Ämter stimmen in keinem Fall mit einer Weihestufe überein - schon die Gliederung dieses Buches trennt Ordo eindeutig von Officium»: P. LANDAU, Die Ursprünge des Amtsbegriff, 10. Observa P. LANDAU, ibid., 10, que un elemento básico del Liber extra fueron las Compilationes antiquae elaboradas entre 1128 y 1126; cada una de las compilationes incluye títulos con la rúbrica de officio. No mucho más tarde del año 1000 se compuso en Italia una Collectio de ecclesiasticis officiis que regula una variedad de cargos, como los de arcbidiaconus, archipresbyter, primicerius, sacrista, custos. Landau edita los textos en las páginas 50-54 del estudio citado, donde se demuestra la influencia de esta colección de textos apócrifos y de Bernardo de Pavía en el Liber Extra de Gregorio IX.

42 Cfr. CIC de 1983 , c. $131 \S 1$. «Potestas regiminis ordinaria ea est, quae ipso iure alicui officio adnectitur; delegata, quae ipsi personae non mediante officio conceditur». 
prueba de la delegación, su extinción. En resumen, el término oficio designa en X.1.19 la actividad delegada, sin mezclar el oficio con la delegación ${ }^{43}$.

En el elenco de oficios del libro I de las decretales de Gregorio IX, destaca por su planteamiento el título 23 dedicado al archidiácono: De officio archidiaconi. En el siglo XIII el archidiaconus o arcediano está consolidado en muchas diócesis como el cargo más importante después del obispo, por lo que se refiere a la administración ${ }^{44}$. Muchos autores lo consideran el precedente del oficio de vicario general, que surgió más tarde, aunque esta opinión fue criticada hace algunas décadas por Edouard Fournier, quien afirmó que el vicario general procede de la extensión de la figura del procurator generalis del derecho romano al ámbito eclesiástico y tuvo un origen autónomo respecto al archidiaconus, que ciertamente fue desapareciendo de la organización de las diócesis a medida que se generalizó la figura del vicario general ${ }^{45}$. Pero con independencia de su origen y decadencia, el oficio de archidiaconus es el colaborador del obispo que resulta mejor perfilado en el Liber Extra, sobre todo si se compara con la menor atención que le prestó el Decreto de Graciano, a pesar de que ya en la alta edad media se trataba del cargo más importante de las diócesis después del obispo ${ }^{46}$.

En efecto, el título 23 del libro I determina lo que corresponde al oficio del arcediano por lo que se refiere al ámbito litúrgico y también a la cura de almas, aunque no actúa por autoridad propia sino como vicarius episcopi. Participa además en la administración de la diócesis, visita las iglesias de su demarcación, e incluso puede imponer penas, aunque no de ecclesiastica institutione, por derecho común, sino con la autoridad del obispo ${ }^{47}$. Es expresivo de la importante posición del oficio del archidiaconus que las decretales se vean obligadas a precisar también qué funciones quedan excluidas de su competencia ${ }^{48}$. Ade-

43 La distinción entre la potestad ordinaria y la delegada está apuntada en X.1.29.5 y 7.

${ }^{44}$ Sobre el archidiaconus, además del estudio de Landau ya citado, cfr. B. BASDEVANT-GAUdEMET, L'archidiacre et l'archiprête d'après le Décret de Gratien, en EADEM, Église et Autoritès. Etudes d'bistoire de droit canonique médiéval, cit., 177-198; y para una visión general, A. AMANIEU, Archidiacre, en Dictionnaire de droit canonique 1 (1935), cols. 948-1004.

${ }^{45}$ Cfr. E. Fournier, L'origine du vicaire général et des autres membres de la curie diocésaine, Chez l'Auteur, Paris 1940, 299-318.

${ }^{46}$ Cfr. P. Landau, Die Ursprünge des Amtsbegriff, 14; sobre los oficios diocesanos en las decretales de Gregorio IX, cfr. D. E. HeINTSCHEL, The mediaeval concept of an ecclesiastical office, Catholic Univ. of America Press, Washington 1956, 61-69.

${ }^{47}$ Cfr. X.1.23.1-7, especialmente.

${ }^{48}$ Cfr. X.1.23.7. 
más, no faltan decisiones sobre las relaciones orgánicas con otros cargos, como cuando se precisa que el primicerius y el arcipreste están subordinados al archidiácono ${ }^{49}$.

Sin embargo, estas fuentes sólo tratan propiamente de los oficios unipersonales. En efecto, los tradicionales órganos colegiados de la Iglesia, como los concilios y sínodos, el colegio de los cardenales y el cabildo de canónigos, frecuentemente mencionados en las fuentes, carecen de una regulación de conjunto semejante al menos a la de los oficios unipersonales ${ }^{50}$. En ausencia de una regulación detallada de esas competencias colegiales, queda en el Corpus iuris canonici un tratamiento jurídico de esos entes con ocasión de su necesaria participación en procedimientos jurídicos como el desarrollo de procesos electorales, o el otorgamiento de consejo o consentimiento para determinados actos ${ }^{51}$.

En resumen, el derecho de las decretales en la primera mitad del siglo XIII, apunta una sistemática de la organización eclesiástica que ha sido relevante desde entonces para el derecho canónico. La Iglesia aprovecha en su organización la distribución de oficios como centros abstractos de competencias que no ahogan la relevancia del elemento personal, tan importante en la vida de la Iglesia, pero sí garantizan la continuidad de las tareas y la extensión de una organización pastoral en ciudades y campos.

\section{EvOLUCiÓN DE LAS IDEAS SOBRE EL OFICIO ECLESIÁSTICO}

Resulta de interés detenerse en el examen de las ideas expresadas de manera más o menos explícita a lo largo de la evolución del oficio como institución canónica. Evidentemente, no cabe aquí una valoración detallada, pues al tratarse de un elemento central en el derecho canónico constitucional y administrativo, apenas hay instituciones con las que el oficio no tenga relación. Pensemos en la misma realidad de la potestad eclesiástica en sus diversas manifestaciones, los entes colegiales y su organización interna, o la relación del oficio con la personalidad jurídica pública.

Históricamente la figura del oficio fue soporte de la consolidación del episcopado monárquico en las Iglesias particulares. Pero esta cuestión, aunque significativa, nos llevaría demasiado lejos, como también, por ejemplo, el es-

\footnotetext{
Cfr. X.1.25.cap.un.

${ }^{50}$ Cfr. P. Landau, Die Ursprünge des Amtsbegriff, 48.

${ }^{51}$ Cfr. ibid.
} 
tudio de la formación y desarrollo del principio territorial, que configura los principales oficios al servicio de comunidades eclesiásticas, delimitadas y distintas unas de otras, en distintos lugares.

Así las cosas, se puede recordar principalmente la virtualidad del oficio en la distinción clásica de las potestades de orden y de jurisdicción. Otra cuestión que merece la pena valorarse es la contribución del oficio a un inevitable y necesario proceso de "despersonalización" en la promoción del bien común de la Iglesia. Finalmente, será oportuno también mencionar la figura del beneficio eclesiástico, una institución con la que el oficio estuvo vinculado durante tantos siglos. Estos tres elementos -potestad, estabilidad institucional y patrimonio- abren una ventana desde la que se contemplan características históricas del oficio como institución general del derecho canónico.

\subsection{El oficio como instrumento principal para la organización y ejercicio de la potestad eclesiástica de orden y de jurisdicción}

Graciano trata del oficio en relación con el sacramento del orden, mientras que no sucede lo mismo en el derecho de las decretales donde se advierte una separación sistemática entre orden sagrado y titularidad de los cargos, como hemos estudiado en el apartado anterior. Según la distribución de los correspondientes títulos de las decretales, el oficio deja de ser una consecuencia necesaria de la recepción del orden sagrado y pasa a tener una regulación independiente ${ }^{52}$. Cosa distinta es que la mayoría de los cargos sean ejercidos por clérigos, pero conceptualmente el sacramento del orden y el oficio son instituciones distintas en las decretales.

Pero además de ser una institución conceptualmente diferenciada del sacramento del orden, el oficio es también independiente en cuanto tal de la potestad eclesiástica. En efecto, en la evolución histórica del oficio como institución se evidencia un proceso de gradual desvinculación necesaria del oficio respecto de la potestad. Un claro resultado de esta evolución institucional se comprueba con la comparación entre las versiones del concepto legal de oficio eclesiástico en la codificación del derecho canónico del siglo XX. Según el c. $145 \$ 1$ del CIC de 1917, sólo en sentido amplio podía entenderse un oficio sin potestad, pues estrictamente hablando oficio era una función o cargo

52 Cfr. P. LandaU, Die Ursprünge des Amtsbegriff, 9 y 10. 
constituido establemente por el derecho que «lleva aneja una participación eclesiástica, sea de orden, sea de jurisdicción» ${ }^{53}$. En cambio, el c. $145 \$ 1$ del CIC de 1983 renuncia a la distinción entre oficio en sentido amplio y estricto (lo que no impide su utilidad interpretativa) y establece un concepto legal de oficio desvinculado del eventual ejercicio de la potestad eclesiástica ${ }^{54}$.

Evidentemente este proceso histórico de desvinculación es conceptual y no excluye la consideración del oficio como un instrumento general de la potestad eclesiástica. No todos los oficios comportan la titularidad de la potestad de orden o la de jurisdicción, pero los oficios más importantes llevan unida la potestad de régimen. En efecto, la relación entre el oficio y la potestad eclesiástica es una realidad histórica, en buena medida paralela a la elaboración de una eclesiología excesivamente articulada sobre la base del sacramento del orden sagrado en perjuicio de la relevancia del sacramento del bautismo. Según la visión tradicional, de orientación "jerarcológica” o estamental, la Iglesia sería ante todo una sociedad desigual, jerárquicamente organizada por la distinción entre el estado clerical y el estado laical. La diversidad producida en la sociedad eclesiástica por el sacramento del orden sería el presupuesto para cualquier otra consideración. En tal concepción el acento recaería no tanto en las funciones y su ordenación jurídica, cuanto más bien en la diversidad personal causada por el sacramento del orden. De ahí la equivalencia práctica entre las funciones de la organización eclesiástica y las funciones clericales, es decir, propias de los ordenados como personas, según lo que a veces se ha denominado visión personalista o estamental de la organización eclesiástica ${ }^{55}$.

La distinción entre la potestad derivada del orden sagrado y la potestad de jurisdicción será un elemento central en las ideas subyacentes bajo la evolución histórica del oficio. La distinción entre ambas potestades y también su debida relación; es decir, ¿̇en qué medida el sacramento del orden es condición

${ }^{53}$ «Officium ecclesiasticum lato sensu est quodlibet munus quod in spiritualem finem legitime exercetur; stricto autem sensu est munus ordinatione sive divina sive ecclesiastica stabiliter constitutum, ad normam sacrorum canonum conferendum, aliquam saltem secumferens participationem ecclesiasticae potestatis sive ordinis sive iurisdictionis».

${ }^{54}$ Cfr. el c. $145 \$ 1$ del CIC de 1983: «Officium ecclesiasticum est quodlibet munus ordinatione sive divina sive ecclesiastica stabiliter constitutum in finem spiritualem exercendum». En el mismo sentido el c. $936 \$ 1$ del CCEO: «In Ecclesia officium est quodlibet munus ab ipso Domino vel ab auctoritate competenti stabiliter constitutum in finem spiritualem exercendum».

55 Este planteamiento fue descrito y criticado agudamente por Javier Hervada. Veáse, por ejemplo, Estructura y principios constitucionales del gobierno central de la Iglesia, entrevista originalmente publicada en Ius Canonicum 11 (1971) 11-55; ahora en J. Hervada, Vetera et nova. Cuestiones de derecho canónico y afines (1958-2004), 2ª ed., Pamplona 2005, 187-233, especialmente 189-197. 
necesaria para la titularidad y el ejercicio de la potestad en la Iglesia? La respuesta a esta pregunta es compleja desde el punto de vista histórico, canónico, teológico, y afecta también a la explicación de la naturaleza del oficio eclesiástico, que durante la historia de la Iglesia ha sido largamente concebido como una institución clerical, aunque hoy ya no es así.

Es sabido que la terminología sobre las potestades de orden y de jurisdicción fue asentándose en los textos de la Iglesia a lo largo del segundo milenio. Según la explicación tradicional, la potestad de orden se recibe a través del sacramento del orden sagrado y se ejerce en los sacramentos y demás actos del culto divino; mientras que la de jurisdicción se trasmite y recibe a través del acto jurídico de la autoridad eclesiástica llamado misión canónica que asigna los súbditos sobre la que podrá ejercerse, pues se destina al gobierno de la Iglesia. La primera daba lugar a la jerarquía de orden, formada por los obispos, presbíteros y diáconos; la segunda a la jerarquía de jurisdicción: el papa, los obispos y los titulares de oficios que participaban en la potestad pontificia o episcopal ${ }^{56}$. Por tener un origen sacramental, la potestad de orden es inamisible, mientras que la de jurisdicción puede perderse al cesar en el oficio o por revocación de la misión canónica si se tratara de una delegación. Además, la primera no está sujeta de suyo a los límites espaciales (determinados territorios) o personales (determinadas personas) que se dan en cambio en el ejercicio de la jurisdicción eclesiástica.

Un esquema clásico -en el que era elemento básico la figura del oficio-, consistía en distinguir la jerarquía de orden de la de jurisdicción. En la jerarquía de orden se incluía la distinción entre estado clerical y estado laical, y desde ella se llegaba al estudio del orden sagrado y de los derechos y obligaciones de los clérigos en sus distintos grados. Por su parte, en la jerarquía de jurisdicción se incluían unas nociones generales acerca de los oficios eclesiásticos, sobre todo en lo que se refiere a su institución, provisión y pérdida, y después ya se trataba de cada uno de los oficios con jurisdicción aneja, desde el papa hasta los párrocos ${ }^{57}$. Según esta explicación, el oficio eclesiástico podía considerarse precisamente como un instrumento jurídico-canónico al servicio de dos finalidades básicas: por una parte, la organización estable de las potestades

${ }^{56}$ Cfr. c. $108 \$ 3$ del CIC de 1917.

57 Éste es el esquema que seguía Wernz en su Ius decretalium: cfr. F. X. Wernz, Ius decretalium ad usum praelectionum in scholis textus canonici sive iuris decretalium, II, Ius constitutionis Ecclesiae catholicae, Romae 1899. 
de orden y de jurisdicción; por otra parte, su distribución ordenada a favor de diversos sujetos.

Aunque la distinción entre orden y jurisdicción se desarrolló de modo reflejo y explícito en paralelo a la formación de una verdadera ciencia canónica a partir del siglo XII, se ha demostrado suficientemente que no se trata de una distinción medieval, sino que tiene sólidas raíces en la Iglesia antigua ${ }^{58}$. La historia de las instituciones eclesiásticas del primer milenio prueba precisamente la incidencia del oficio eclesiástico en la trasmisión y recepción de la potestad. La doctrina de las dos potestades de orden y de jurisdicción sólo pudo ser elaborada con ocasión del nacimiento de la ciencia canónica, ambientada en las primeras universidades medievales, pero históricamente es anterior a esa doctrina la existencia de una doble vía de trasmisión de la potestad en la Iglesia: por una parte, el oficio y, por otra, el orden sagrado. De antiguo, la Iglesia ha reconocido que, junto al orden sagrado y la potestad correspondiente, existía una potestad distinta, unida al oficio y no a la persona ${ }^{59}$.

A veces no faltaron abusos cuando la distinción entre el sacramento del orden y la potestad del oficio era llevada hasta el extremo de una verdadera separación, con consecuencias inaceptables sobre todo desde la doctrina católica sobre la naturaleza y la finalidad del episcopado, que impide una separación de funciones y poderes al estilo de la organización política del Estado moderno ${ }^{60}$. Recuérdense también los casos de obispos que renunciaban no sólo a las funciones propias del orden sagrado, sino también al ejercicio del gobierno, tras

${ }^{58}$ Remito a la síntesis que he intentado en El problema de la participación de los laicos en la potestad de régimen. Dos vías de solución, Ius Canonicum 54 (2014) 607-612, especialmente, según testimonios de historiadores del derecho canónico.

${ }^{59}$ Por decirlo con palabras de Stickler, «nullum ergo dubium esse potest quin, etiam in primo Ecclesiae millennio, quamvis nulla adhuc doctrina recognita de potestatis sacrae natura et distinctionibus theoretice enucleata esset, de facto tamen duplex hierarchia et duplex potestas exsisterit, altera ordinis, altera regiminis; illa cum ordine, haec cum officio conferenda, illa personae, haec officio inhaerens»: A. M. STICKLER, De potestatis sacrae natura et origine, Periodica de re morali, canonica, liturgica 71 (1982) 71. Como dice también Condorelli, sería equivocado considerar la historia de la bipartición de la potestad eclesiástica partiendo exclusivamente del concepto de iurisdictio, pues ese concepto tiene una prehistoria: cfr. O. CONDORELLI, Ordinare-iudicare. Ricerche sulle potestà dei vescovi nella Chiesa antica e altomedievale (secoli II-IX), Roma 1997, 11.

${ }^{60}$ No fue infrecuente que pasara mucho tiempo antes de que los obispos-príncipes alemanes, dedicados a lo largo de la edad media tanto a negocios eclesiásticos como estrictamente seculares, recibieran el orden episcopal o incluso que no fueran obispos: pertenecían en todo caso al estado clerical, para lo que bastaba la tonsura o alguna de las órdenes menores, y en caso necesario, asumiendo el título de la diócesis, se hacían representar por obispos auxiliares en los aspectos propios del culto y del orden sagrado (cfr. A. M. STICKLER, La bipartición de la potestad eclesiástica en su perspectiva histórica, Ius Canonicum 29 [1975] 53; IDEM, De potestatis sacrae, 80 y 87). 
haber tomado posesión de la diócesis (y del correspondiente beneficio con sus rentas); de hecho, a veces ni siquiera residían en ella, sino que trasmitían la jurisdicción a un obispo auxiliar o vicario. Esta experiencia está en la base de la reafirmación histórica disciplinar de la ley de residencia de los obispos, que encontró su cumbre en el siglo XVI con el Concilio de Trento. Pero más allá de estos supuestos abusivos, la distinción entre el oficio y el orden sagrado, en paralelo a la distinción y relación del oficio con la potestad, se manifiesta como característica notable en la evolución histórica del oficio como institución.

A lo largo del segundo milenio el desarrollo progresivo y altamente elaborado de la distinción entre ordo, iurisdictio y officium llegó a ser doctrina común aceptada por canonistas y teólogos, por lo que no es necesario detenerse en su evolución ${ }^{61}$. La distinción fue formalizada con toda claridad por el CIC de $1917^{62}$. De este modo, la Iglesia fue identificando cada vez con más precisión los aspectos de la potestad de jurisdicción y sus modalidades legislativa, ejecutiva y judicial, sin perjuicio de la concentración radical de esas expresiones jurisdiccionales en el oficio primacial romano y en el oficio capital diocesano. Otro claro progreso fue el de la clasificación de la potestad de jurisdicción en ordinaria y delegada, propia y vicaria, distinciones incluidas en las fuentes antiguas y en la codificación del siglo XX, y que precisamente se valen del oficio eclesiástico como criterio clasificatorio primordial ${ }^{63}$.

\section{2. "Universitas", "officium". El valor institucional y no meramente subjetivo del oficio}

De acuerdo con la concepción jerarcológica o personalista de la jerarquía eclesiástica, a la que antes me he referido, el oficio podía fácilmente perder su carga pública e institucional, para ser concebido más bien como una situación subjetiva con relevancia jurídica: el derecho a ejercer el orden sagrado según la concreta tarea que el clérigo recibiera. Con ese planteamiento, entre otras consecuencias, era imposible que los laicos pudieran ejercer verdaderos oficios

${ }^{61}$ Cfr. abundantes referencias en L. VILLEMIN, Pouvoir d'ordre et pouvoir de juridiction: Histoire théologique de leur distinction, Les Éditions du Cerf, Paris 2003.

${ }^{62}$ Para el sistema del CIC de 1917, cfr. especialmente los cc. $108 \$ 3$ (jerarquía de orden y de jurisdicción), 109 (acceso a los grados de la jurisdicción en el caso del Papa y de otros oficios), 118, 196, 219 (momento en el que el Papa recibe la jurisdicción suprema), $329 \$ 1$ (institución divina del episcopado al frente de las Iglesias particulares) y 948.

${ }^{63}$ Cfr. CIC de 1917, c. $197 \$ 2$; CIC de 1983 c. 131; CCEO, c. 981. 
(por más que la distinción ordo-iurisdictio pudiera justificar teóricamente esa posibilidad). El oficio era una situación jurídica clerical y específicamente la que era característica de los miembros de la jerarquía sagrada ${ }^{64}$.

En el derecho canónico se da una cierta tensión entre la necesidad de contar con categorías abstractas que despersonalicen el ejercicio de las funciones públicas al servicio de la comunidad y el acento fuertemente personal de la potestad eclesiástica, que tiene además, en los oficios capitales, una base sacramental; es decir, un origen ligado al sacramento del orden, que solamente puede ser recibido por una persona física. $\mathrm{Si}$, por una parte, la continuidad de las funciones y la protección del bien común son incompatibles con la privatización de los servicios eclesiales, como si fueran algo meramente individual y subjetivo, por otra parte, esos servicios se ejercen radicalmente en nombre de Jesucristo, desde los más modestos hasta los que tienen una mayor relevancia social. En este sentido la categoría del oficio eclesiástico ha servido históricamente para dar continuidad según derecho a las responsabilidades comunes, más allá de las personas que las ejerzan concretamente en las distintas circunstancias históricas; al mismo tiempo, el instrumento conceptual del oficio permite, al menos en parte, una despersonalización (Entpersönlichung) de la esfera pública de funciones ${ }^{65}$. Esto tiene diversas consecuencias en lo relativo al modo de concebir las tareas del oficio e incluso su misma estructura, en la que junto al imprescindible elemento funcional debe incluirse también un elemento personal que define internamente nuestra institución. Es mérito histórico del derecho canónico haber encontrado formas transpersonales de ejercicio de la autoridad, frente a la alternativa de desempeños del poder meramente carismáticos, personales e inevitablemente arbitrarios ${ }^{66}$. El oficio unipersonal, por una parte, y el principio jurídico de la colegialidad, por otra, han sido los dos elementos básicos de este necesario proceso de despersonalización que ha contribuido a objetivar la estructura jurídica de la Iglesia.

En efecto, la ciencia canónica se ha servido históricamente de nociones expresivas de esa continuidad más allá de los individuos, como son las de officium y universitas. La cuestión es también significativa desde el punto de vista de la historia de las ideas políticas, como se comprueba en la famosa metáfora

${ }^{64}$ Cfr. J. HervaDA, Estructura y principios constitucionales del gobierno central de la Iglesia, cit., 195.

${ }^{65}$ Cfr. U. Wolter, Amt und Officium in mittelalterlichen Quellen vom 13. bis 15. Fabrhundert, Zeitschrift der Savigny-Stiftung für Rechtsgeschichte. Kanonistische Abteilung 74 (1988) 264.

${ }^{66}$ Cfr. C. Fantappì, Ecclesiologia e canonistica, Marcianum Press, Venezia 2015, 114. 
de Ernst Kantorowicz sobre los dos cuerpos del rey según la doctrina política medieval: uno perecedero, humano, natural, y el otro político, inmortal, continuo a través de la historia; a esta doctrina sobre la permanencia de la institución monárquica se llegó mediante una marcada influencia de la doctrina corporativa de los juristas medievales y señaladamente de los canonistas ${ }^{67}$. Si la noción de officium (y también la de beneficium) explica la continuidad de la función encomendada a una persona, la de universitas se refiere a una pluralidad de miembros que actúan esa función de manera conjunta y unitaria.

Para los juristas medievales la universitas es el nombre genérico de la comunidad, aunque muchas veces se empleaban términos similares como collegium, societas, corpus $^{68}$. A través de ellos se designan colectividades que actúan en la vida eclesiástica. Lo que nos interesa ahora es destacar la idea de continuidad, resumida en la expresión universitas non moritur. La universitas (o collegium) es idéntica materialmente a los individuos que la componen, pero no formalmente, de modo que tiene la capacidad de permanecer en el tiempo. Estamos en los albores de la doctrina de la personalidad jurídica ${ }^{69}$.

Incluso antes de los civilistas, los canonistas habían profundizado en la personificación de colectividades como los cabildos y otros colegios. La personificación de las universitates implicaba el aspecto de la perpetuidad de esas corporaciones. Aunque los miembros hubiesen ya fallecido y las personas de hoy no fueran las de ayer, la iglesia, el cabildo, el colegio, permanecerían independientemente de la sucesión de personas: universitas non moritur ${ }^{70}$. Por lo tanto, lo esencial en la universitas no era constituir una simple agrupación de personas, sino la capacidad de actuar permanentemente, de tal manera que a pesar de los cambios personales pudiera mantener su identidad corporativa ${ }^{71}$.

Lo mismo en el caso del oficio. Universitas non moritur y también, dignitas non moritur. A pesar de diversos matices, los términos de officium y dignitas

${ }^{67}$ Cfr. E. H. Kantorowicz, The king's two bodies. A study in mediaeval political theology, Princeton University Press, Princeton NY 1957. Hay traducción española: Los dos cuerpos del rey: un estudio de teología política medieval, Alianza, Madrid 1985. Sigue siendo también de utilidad la consulta del clásico estudio de Otto vON GIERKE, especialmente por lo que se refiere a la aportación de los canonistas medievales a las doctrinas colegiales: Das deutsche Genossenschaftsrecht, vol. 3, Graz 1954 (reimpr. de la ed. original de 1881): Die Korporationstheorie der Kanonisten, 238-351.

${ }^{68}$ Cfr. P. Michaud-Quantin, «Universitas». Expressions du mouvement communautaire dans le moyen-age latin, Libraire philosophique J. Vrin, Paris 1970, 6, 70-75.

${ }^{69}$ Cfr. ibid., 207-211.

${ }_{71}^{70}$ Cfr. E. H. Kantorowicz, The king's two bodies (sobre la base del estudio de Gierke), 302-313.

${ }^{71}$ Cfr. ibid., 311-313. 
se consideraban con frecuencia equivalentes ${ }^{72}$. Lo que se aplicaba a la dignidad era aplicable también al cargo mismo, de tal manera que los comentarios de los canonistas del siglo XIII se referían a la dignitas antes que al officium ${ }^{73}$.

Un texto sobre el que volvieron una y otra vez los canonistas medievales fue la decretal Quoniam abbas, de Alejandro III, de la que ofrezco una traducción más bien literal:

«Ya que el abad de Leicester -el cual prefijó a las partes un día para actuar antes de recibir nuestro mandato, tras haber obtenido el consejo de prudentes- tomó como socio suyo en el conocimiento de la causa al abad de Winchester, en sustitución de un juez que había muerto, tras extenderle [al abad de Winchester] nuestro mandato y puesto que la carta de comisión había sido emanada por mi parte según indicación de lugares y no de personas, por todo ello, tenemos por rata y firme la sentencia de aquéllos, como es justa» ${ }^{74}$.

La decretal confirmaba la sentencia en la que habían intervenido los abades de Leicester y de Winchester, este último en sustitución de un juez que había muerto. La razón de esa confirmación consistía en que la comisión para actuar como jueces había sido concedida por el papa a aquellos abades con expresa mención de los lugares (es decir, de sus cargos en aquellas abadías) y no de las personas singulares. Una cosa era la delegación con mención del nombre propio y otra distinta la que no mencionaba así al destinatario: delegatio facta personae, o bien facta dignitati. La primera se extinguía con quien la hubiera recibido; la segunda, en cambio, continuaba en el sucesor. Quedaba así formulada la sucesión en las tareas encomendadas ${ }^{75}$.

Los comentarios de los canonistas medievales sobre esta decretal subrayaron que cuando la comisión hubiera sido hecha a la dignidad o cargo sin ex-

\footnotetext{
${ }^{72}$ Juan de Andrés: ad X.3.5.28: «Sciendum est quod dignitas et personatus et officium videntur synonima», citado por E. H. KANTOROWICZ, The king's two bodies, 384, nota 231.

${ }^{73}$ Cfr. ibid., 385.

${ }^{74}$ X.1.29.14 (ed. Friedberg, II, 162): «Quoniam abbas Leicestriae, qui prius suscepto mandato nostro partibus diem ad agendum praefixit, praehabito consilio prudentum, abbatem Vincestriae de novo substitutum iudici praemortuo, illi mandato nostro porrecto, quia sub expressis nominibus locorum et non personarum commissio literarum a nobis emanavit, sibi socium in causae cognitione adiunxit, ideo nos sententiam illorum, sicut est iusta, ratam et firmam habemus».

75 En la codificación canónica del siglo XX esta solución ha sido regulada en el marco de las normas generales sobre la potestad de régimen en los cc. 66 \$2 y $197 \$ 1$ del CIC de 1917, y cc. 131 $\$ 1$ y $132 \$ 2$ del CIC de 1983 .
} 
presar el nombre propio, pasaría al sucesor: delegatio facta dignitati, non expresso nomine proprio, transit ad successorem. La razón era explicada por la glosa ordinaria de Bernardo de Parma al Liber Extra: el predecesor y el sucesor han de considerarse una sola persona, ya que la dignidad no muere ${ }^{76}$. Esto no se aplicaba solamente a los actos de delegación en sentido estricto (o sea, una comisión meramente personal), sino también a la potestad de los distintos cargos y también a las obligaciones contraídas en nombre del oficio. Una cosa era el aspecto individual del titular de la dignitas u officium, su personalidad y derechos como individuo, y otra distinta su responsabilidad como gobernante. Por esta vía se fue distinguiendo claramente la posición de la persona en cuanto titular del cargo y en cuanto persona individual. Cino de Pistoia explicaba que el obispo tiene dos personalidades: una en cuanto que es obispo, otra como Pedro o Martín; de este modo el acento se ponía en la correspondiente responsabilidad estable al servicio de la Iglesia ${ }^{77}$.

La dignitas u oficio cumplía exactamente la misma función de continuidad en la atención de tareas y servicios que la universitas, aunque a diferencia de ella mediante un solo titular. Un titular único que habría de distinguirse respecto a la tarea misma, puesto que ésta continuaría a pesar de la muerte, traslado o remoción de la persona, ya que otra vendría a ocupar su lugar: quia dignitas numquam perit, individua vero quotidie pereunt ${ }^{78}$. Juan de Andrés, y con él tantos canonistas, aplicaba esto al papado: la persona del papa verá la muerte, pero el papado, en cuanto dignidad o imperio siempre permanece ${ }^{79}$. En el contexto de la doctrina del romano pontífice como vicario de Cristo -título atribuido al papa ya en el siglo XI y consolidado en el siglo siguiente- la continuidad del papado fue referida siempre al oficio, no a la persona ${ }^{80}$.

En efecto, este planteamiento ha tenido importancia en la evolución del papado. Aquí es esencial la distinción entre la persona física y el oficio mis-

${ }^{76}$ Glos. ord. ad X.1.29.14, v. substitutum: «...quia [praedecessor et successor] pro una persona intelliguntur: quia dignitas non moritur»: cfr. E. H. KANTOROWICZ, The king's two bodies, 386, nota 236.

77 «Episcopus habet duas personas, unam personam inquantum est episcopus, alteram inquantum est Petrus et Martinus»: en O. vON GIERKE, Das deutsche Genossenschaftsrecht, vol. 3, 363, nota 34.

${ }^{78}$ Cfr. los textos alegados por O. vON GIERKE, Das deutsche Genossenschaftsrecht, vol. 3, 271, n. 73.

79 «Tenens papatum vel dignitatem est corruptibilis, papatus tamen, dignitas vel imperium semper est»: Novella super Sexto: VI.1.3.5: ibid., 271, nota 73.

${ }^{80}$ En el siglo XIV Augustinus Triumphus: el papa representa a Cristo «ut vicarius eius in officio et potestate non in persona»: cfr. M. MACCARRONE, Vicarius Christi. Storia del titolo papale, Lateranum. Nova series, Romae 1953, 85 ss., y 198 para la cita de Triumphus. 
mo. El papa no es una persona que sucede a otra, al estilo de un rey que viene después de otro rey: el papa es el sucesor de Pedro, cada papa lo es ${ }^{81}$. A partir del papa Inocencio III (1198-1216) con la afirmación de la monarquía papal, desaparecerá de la cancillería pontificia el título de vicario de Pedro, sustituido por el de Vicario de Cristo ${ }^{82}$. Recuérdese también concretamente la cuestión de la infalibilidad pontificia: no es infalible el papa como persona, sino en cuanto titular de un cargo y, además, con unas condiciones de ejercicio formalizadas escrupulosamente siglos más tarde por el Concilio Vaticano I.

Se puede afirmar que la figura del oficio ha servido para la configuración del papado y también a la inversa, puesto que en ningún otro caso resplandece con más claridad la distinción entre el oficio y su titular. «El papado es un oficio revestido por una persona y no propiamente una persona que viste un oficio, aunque llegue a ser su titular» ${ }^{83}$. En esta cuestión canónica hay importantes implicaciones teológicas e históricas, como por ejemplo la conducta muy poco ejemplar de algunos papas en el pasado, en cuya interpretación es decisiva la distinción elemental entre la sede y el sedente, entre el oficio y la persona ${ }^{84}$. Por la naturaleza teológica de la Iglesia, esta convicción se hacía depender en lo fundamental de la providencia divina: quia Christus non moritur ${ }^{85}$.

A través de diversas vías y expresiones, el oficio se ha configurado históricamente como una institución de derecho público objetivo, un instrumento para asegurar la continuidad y estabilidad de las tareas dirigidas al bien común. Tareas de caridad, culto y enseñanza, pero también de gobierno, que lejos de conceptuarse como objeto de libre disposición individual, son entendidas propiamente como responsabilidades que se ejercen en nombre y al servicio de la Iglesia.

${ }^{81}$ Cfr. W. Ulmann, The medieval papacy, St Thomas and beyond, original de 1960, ahora en IDEM, Law and jurisdiction in the Middle Ages, Variorum Reprints, London 1988, 3.

82 Cfr. J. Gaudemet, Storia del diritto canonico. Ecclesia et civitas, trad. it., San Paolo, Torino 1998, 383; y el clásico estudio de M. MACCARRONE, ya citado.

83 C. FANTAPPIE, Ecclesiologia e canonistica, 363.

${ }^{84}$ Cfr. ibid., 370. La distinción entre oficio y titular en el munus del Romano pontífice ha sido replanteada a propósito de la renuncia papal: cfr. G. BonI, Sopra una rinuncia. La decisione di papa Benedetto XVI e il diritto, Bononia University Press, Bologna 2015, 172-184.

${ }^{85}$ Así Juan de Andrés: Novella, s. X.2.12.4: «Licet moriatur praelatus et omnes clerici in ecclesia, dominium illorum non vacat, quia Christus non moritur, nec potest ecclesia deficere», en E. H. Kantorowicz, The king's two bodies, 396, nota 277. 


\subsection{Oficio y beneficio}

Un elemento importante en la evolución histórica del oficio es su relación especial con la institución distinta, pero durante siglos estrechamente relacionada, del beneficio eclesiástico. Una figura que fue regulada por el derecho canónico para organizar hasta donde fuese posible la retribución de los sacerdotes al servicio de las diócesis, y más ampliamente, al frente de tareas estables de culto, pastoral o gobierno.

El origen del beneficio eclesiástico como tal no es perfectamente claro, pero se vincula a la sustentación del clero, especialmente el dedicado a la cura de almas ${ }^{86}$. Ese origen suele ponerse en relación con la influencia del derecho y las costumbres de los pueblos germánicos tras la desaparición del imperio romano en occidente y las conversiones masivas al cristianismo, en un periodo que comprende básicamente los siglos VII y VIII. Esa influencia se manifestó en la constitución de diversas masas patrimoniales en las diócesis, sujetas a un régimen privado de administración y atendidas por distintos oficios y personas ${ }^{87}$.

Una de las cuestiones que la Iglesia de los siglos IV y V debió resolver, una vez reconocida la libertad pública para la evangelización en un mundo que no pocas veces lo impedía hasta entonces, fue la cuestión de la debida administración de los bienes de que iba disponiendo, y también los fines de sustentación del clero y obras de caridad. Se trataba de lugares de culto y reunión, sepulturas, hospitales, orfanatos, hospederías. Propiamente los bienes pertenecían a la Iglesia local y el obispo era el responsable de su administración ${ }^{88}$.

En la España visigoda y en la Francia carolingia el sacerdote frecuentemente no recibía solamente el fruto de una dote, sino también parte de algunas tierras, propiedad de la Iglesia local, que se denominaban en el siglo $\mathrm{X}$ «presbyteratum, feudum presbyterale, beneficium» ${ }^{89}$. Es entonces cuando puede empezar a hablarse de beneficio eclesiástico, que, por otra parte, no se consolidó hasta los siglos XI y XII, y no fue una institución que se aplicara de manera uniforme en todas las iglesias,

${ }^{86}$ Cfr. V. DE ReINA, El sistema beneficial, Gómez, Pamplona 1965, 101-201. La lectura de estas páginas confirma la complejidad de la problemática beneficial desde el punto de vista histórico, sobre todo por lo que se refiere a la distinción entre beneficio secular y eclesiástico, la relación con la institución paralela de las iglesias propias y la diversidad de situaciones locales, aunque el autor se refiere aquí especialmente a la experiencia medieval española.

87 Cfr. A. M. STICKLER, Historia del derecho canónico, en Sacramentum mundi, II, trad. esp., Barcelona 1972, 196-197.

${ }^{88}$ Cfr. J. Gaudemet, Storia del diritto canonico, 128 y 129; D. E. Heintschel, The mediaeval concept of an ecclesiastical office, 7 ss.

89 Cfr. J. Gaudemet, Storia del diritto canonico, 235. 
ya que en muchas seguía vigente el sistema de ofrendas voluntarias, estipendios y diezmos como aportación a las necesidades de la Iglesia y de sus ministros.

Ya en la baja edad media, y salvando siempre el dato de la falta de uniformidad en todas las diócesis, allí donde esta figura se asentó la mayor parte de la dotación del clero provenía del beneficio. El beneficio consistía frecuentemente en dotaciones inmobiliarias, fincas rústicas de desigual valor y posibilidades de explotación. En principio los frutos y rentas del fundo bastarían para asegurar el mantenimiento del presbítero, tantas veces el párroco. Para la colación de los beneficios menores, como los que dotaban a canonjías o parroquias, era frecuente el patronato, es decir, el derecho de presentación del titular del beneficio; derecho que correspondía a la persona que había hecho la dotación, mientras que al obispo correspondía la institución en el beneficio, una vez reconocida la idoneidad del candidato ${ }^{90}$.

La vinculación entre oficio y beneficio no siempre se cumplía. La Iglesia antigua había conocido el sistema de las ordenaciones relativas, es decir, el orden sagrado se recibía para la atención de un concreto oficio en un lugar o en una iglesia determinada. Sin embargo, es sabido que en la época carolingia y a partir del siglo XI se celebraban de hecho ordenaciones absolutas, es decir, sin determinación del oficio, a pesar de la doctrina contraria de los concilios, que prohibían la ordenación en tales casos por falta de título justificativo ${ }^{91}$. Pero desde el siglo XII, con Alejandro III e Inocencio III, el titulus de ordenación adquirió otro significado. Ya no consistía propiamente en el oficio correspondiente a la sagrada ordenación, sino que hacía referencia a la sustentación del ordenado, que debía tener recursos económicos suficientes. De este modo, podían admitirse ordenaciones sin oficio de destino, con tal que hubiera una garantía de sustentación del clérigo, garantía que podía consistir en un concreto beneficio sin oficio ${ }^{92}$.

La no infrecuente separación entre oficio y beneficio tuvo también su reflejo en un fenómeno que fue objeto de diversos intentos reformadores de la disciplina, sobre todo en el Concilio de Trento. Me refiero a la posibilidad de que el titular del beneficio fuera dispensado de llevar las cargas del correspondiente oficio; de este modo, se daba el caso de beneficiados que cobraban las rentas, ejercían las obligaciones del oficio mediante un sacerdote represen-

${ }^{90}$ En el ámbito diocesano, se distinguían los beneficios mayores, como la diócesis o la abadía, de otros beneficios menores, aunque pudieran éstos tener cierta importancia. Cfr. ibid., 553, nota 59.

91 Cfr. J. Gaudemet, Storia del diritto canonico, 547-548; A. Viana, Obispos titulares. Elementos de tradición canónica y regulación actual, Ius Canonicum 44 (2004) 516.

92 Cfr. J. Gaudemet, Storia del diritto canonico, 554. 
tante (que a su vez recibía una porción congrua de las rentas), pero ni siquiera residían en el lugar donde radicaba el beneficio; por no hablar del abuso de la acumulación de beneficios claramente incompatibles entre sí por lo que se refería a las funciones de los correspondientes oficios ${ }^{93}$.

Este tipo de situaciones históricas no sólo manifestaban la separación entre el oficio y el beneficio, sino que también provocaban la supremacía de esta última figura, en el sentido de que las cuestiones retributivas y patrimoniales dejaban en la penumbra el valor teóricamente predominante del servicio público y de las tareas que debían atenderse a través del oficio. Era como entender el principio clásico al revés: officium datur propter beneficium. En efecto, según el principio tradicional el beneficio existe por el oficio, como instrumento de retribución del titular y en general de sostenimiento económico de los ministros sagrados; beneficium datur propter officium ${ }^{94}$.

Como ya apunté antes, la institución del beneficio era mencionada en distintos textos del Decreto de Graciano ${ }^{95}$. También se regulaba muy ampliamente en diversas decretales, y no sólo bajo el título específico de praebendis et dignitatibus $^{96}$.

El CIC de 1917 regulaba el oficio y el beneficio en libros distintos. Al oficio dedicaba el título IV del libro I sobre las personas, mientras que las normas sobre el beneficio eran incluidas en el título XXV del libro III, dedicado a "las cosas”. Más concretamente, los cánones cc. 1409 ss. del CIC de 1917 regulaban la figura del beneficio eclesiástico y se distribuían en capítulos, dedicados a la constitución, cambio, supresión y colación de beneficios, derecho de patronato -tan ligado históricamente a la figura del beneficio-, posición jurídica de los beneficiados, renuncia y permuta de beneficios: casi ochenta cánones en total, reguladores de una materia muy compleja que ha desaparecido de la legislación canónica vigente ${ }^{97}$. En un contexto de derecho patrimonial, el beneficio era definido como un «ente jurídico constituido o erigido a perpetuidad por la com-

93 Cfr. J. OrLandis, Historia de las instituciones de la Iglesia católica, Eunsa, Pamplona 2003, 134.

94 In VI 1.2.15. Cfr. F. X. WerNZ, Ius decretalium, II, Romae 1899, 343.

${ }^{5}$ Cfr. C. 1 q. 3 cc. 2 y 9; cfr. también C.12 q.1 c.28 d.p.; C.12 q.2 c.72; C.16 q.3 c.11; C.16 q.7 c.11.

96 X.3.5. Un comentario a este título de las Decretales de Gregorio IX en V. DE REINA, El sistema beneficial, 197-201.

97 Salvo la referencia de derecho transitorio contenida en el c. 1272 del CIC de 1983: «En las regiones donde aún existen beneficios propiamente dichos, corresponde determinar su régimen a la conferencia episcopal, según normas establecidas de acuerdo con la Sede Apostólica y aprobadas por ésta, de manera que las rentas e incluso, en la medida de lo posible, la misma dote de los beneficios, pasen gradualmente a la institución de que se trata en el c. $1274 \$ 1$ ». 
petente autoridad eclesiástica, que consta de un oficio sagrado y del derecho a percibir las rentas anejas por la dote al oficio» (c. 1409 del CIC de 1917). Según el canon siguiente, la dote podía tener un origen y contenido variados: bienes del mismo ente, prestaciones de personas físicas o jurídicas, ofrendas de los fieles al rector del beneficio, derechos de estola, distribuciones corales. Como se ve, oficio y beneficio eran distinguidos en la definición, pero al mismo tiempo eran tratados como elementos de una misma institución: bien entendido que el oficio era el elemento que, teóricamente al menos, debería tener mayor relevancia. Además, existían en el derecho del CIC de 1917 oficios sin beneficio anejo, como sucedía por ejemplo con los oficios de la curia diocesana.

Por lo que se refería a la condición del clérigo titular, el sistema beneficial conjugaba la estabilidad objetiva del beneficio como ente jurídico erigido ${ }^{98}$, con la frecuente perpetuidad subjetiva del beneficiado. En efecto, éste no podía ser removido ad nutum, según el libre criterio de la autoridad y contra su voluntad personal, sino sobre la base de unas causas objetivas y un procedimiento administrativo ${ }^{99}$. En el CIC de 1917 se recogía la distinción entre párrocos inamovibles y amovibles, según, respectivamente, su mayor o menor estabilidad en el oficio $^{100}$. Todavía hoy se regulan en la legislación de la Iglesia latina unos procedimientos sobre la remoción y el traslado de párrocos de claras resonancias beneficiales y que se encuentran en cierta tensión con el principio de libertad reconocida al obispo para la provisión de los oficios diocesanos ${ }^{101}$.

El sistema beneficial permitía una desconcentración del patrimonio eclesiástico y facilitaba buenas dotaciones en favor de la Iglesia y de los fines del patrimonio eclesiástico, ante todo la sustentación de los ministros sagrados. Además, era un sistema preferible al de las iglesias propias y patronatos fundados por señores territoriales, ya que de suyo el sistema beneficial no siempre dependía de la dotación de personas ajenas al gobierno de la Iglesia, lo que suponía una mayor autonomía y libertad para la propia misión ${ }^{102}$. Sin embargo,

Cfr. cc. 1409 y 1414-1418 del CIC 1917.

99 Cfr. U. Wolter, Amt und Officium, 256.

Cfr. c. $454 \$ \$$ 2-5 del CIC de 1917.

101 Compárese el contenido de los cc. 1740-1752 del CIC de 1983, dedicados al traslado y remoción de párrocos, con el principio establecido por el c. 157 del mismo Código, según el cual corresponde al obispo diocesano el nombramiento por libre colación de los oficios en su propia Iglesia particular, salvo que el derecho establezca expresamente otra cosa.

102 Cfr. el juicio incidental de Congar, para quien el sistema de las Eigenkirchen fue catastrófico, pues desde el papado hasta las capillas locales la Iglesia quedó sometida a «un poder de laicos»: Y. M. CONGAR, Falones para una teología del laicado, trad. esp., Barcelona 1965, 308. 
estas ventajas del sistema no superaban sus graves inconvenientes: ante todo, la desigualdad entre los beneficios y las correspondientes rentas, aun tratándose de oficios semejantes (por ejemplo, grandes diferencias entre parroquias ricas y pobres, urbanas y rurales). Era además un sistema que no podía extenderse a todas las diócesis, dadas las diferencias económicas y patrimoniales entre ellas, con lo que quedaban pendientes en muchos casos los fines del patrimonio eclesiástico, no sólo porque no alcanzara suficientemente a la financiación del culto y las obras de caridad, sino también porque no cubría la sustentación de los clérigos dedicados al servicio de las diócesis y parroquias. Además, desde el punto de vista conceptual el sistema beneficial arrastraba la consideración del oficio hacia un marco de derecho privado, a todas luces inadecuado a esta institución, porque la configuraba como un derecho subjetivo antes que un servicio al bien común ${ }^{103}$. Si a esto se añade la consideración de la jerarquía sagrada como una condición personal, propia de los ordenados in sacris, antes que una relación institucional de servicio en la Iglesia, se explica que la doctrina moderna sobre los beneficios resultara enriquecida con numerosos tratados sobre cuestiones relativas a derechos y disputas de todo tipo, hasta las más insignificantes, mientras que, en comparación, la doctrina canónica sobre el oficio como institución resultara más bien escasa ${ }^{104}$.

En fin, ventajas e inconvenientes en tensión que han venido a configurar en la actualidad una noción de oficio purificada, en cierto modo, de sus adherencias privatistas y patrimoniales, y mejor orientada a su finalidad espiritual, de servicio al bien común de los fieles.

La aproximación histórica a la noción de oficio en el derecho canónico permite entender las razones que han justificado el empleo de esta institución jurídica, heredada del derecho romano y orientada a un fin espiritual, para ordenar establemente las funciones eclesiásticas, en particular el ejercicio de la potestad sagrada, y distribuirlas a favor de diversos titulares. El oficio viene a ser así un instrumento jurídico para sostener el desarrollo de la misión de la Iglesia en el mundo.

${ }^{103}$ Recuérdese, por ejemplo, la definición de beneficio que ofrecía Ferraris: «ius perpetuum percipiendi fructus ex bonis ecclesiasticis ratione spiritualis officii personae ecclesiasticae auctoritate Ecclesiae constitutum»: L. Ferraris, Prompta Bibliotheca Canonica, vol. I, Romae 1885, s.v. Beneficium, art. 1, n. 6. La época postridentina llegó a conocer la posibilidad frecuente de la resignatio in favorem, que suponía la renuncia al beneficio en favor de un tercero de libre elección: cfr. J. GAUDEMET, Storia del diritto canonico, 727.

104 Cfr. B. Basdevant-Gaudemet, Office ecclésiastique, 278. 


\section{ANTONIO VIANA}

\section{Bibliografía}

Amanieu, A., Archidiacre, Dictionnaire de droit canonique 1 (1935) 948-1004.

Ambrosio de Milán, Los deberes, Introducción, traducción y notas de D. Ramos-Lissón, Ciudad Nueva, Madrid 2015.

Basdevant-Gaudemet, B., Office ecclésiastique. Repères pour une histoire d'un concept, en EADEM, Église et Autoritès. Etudes d'histoire de droit canonique médiéval, Presses universitaires de Limoges, Limoges 2006, 271-284.

—, L'archidiacre et l'archiprête d'après le Décret de Gratien, ibid., 177-198.

Benson, R. L., The bishop-elect. A study in medieval ecclesiastical office, Princeton University Press, Princeton NY 1968.

BonI, G., Sopra una rinuncia. La decisione di papa Benedetto XVI e il diritto, Bononia University Press, 2015.

CONDORELli, O., Ordinare-iudicare. Ricerche sulle potestà dei vescovi nella Chiesa antica e altomedievale (secoli II-IX), Il Cigno Galileo Galilei, Roma 1997.

—, La distinzione tra potestà di ordine e potestà di giurisdizione nella tradizione canonica bizantina, en Curiosità e rigore. Studi in memoria di Maria Cristina Folliero, a cura di Giuseppe D'Angelo, I, Giappichelli, Torino 2018, 241-271.

CONGar, Y. M., La ferarquía como servicio según el Nuevo testamento y los documentos de la Tradición, en Y. M. CONGAR - B. D. DupuY (eds.), El episcopado y la Iglesia universal, trad. esp. del original francés de 1964, Barcelona 1966.

—, Algunas expresiones tradicionales del servicio cristiano, ibid., 97-126.

DE REINA, V., El sistema beneficial, Gómez, Pamplona 1965.

FANTAPPIÈ, C., Ecclesiologia e canonistica, Marcianum Press, Venezia 2015.

FOURNIER, E., L'origine du vicaire général et des autres membres de la curie diocésaine, Chez l'Auteur, Paris 1940.

Gaudemet, J., Storia del diritto canonico. Ecclesia et civitas, trad. it., San Paolo, Torino 1998.

GiannINI, M. S., Istituzioni di diritto amministrativo (a cura di A. Mirabelli Centurione), $2^{a}$ ed., Giuffrè, Milano 2000.

GIERKe, O. von, Das deutsche Genossenschaftsrecht, vol. 3, Graz 1954 (reimpr. de la ed. original de 1881): Die Korporationstheorie der Kanonisten, 238-351.

Heintschel, D. E., The mediaeval concept of an ecclesiastical office, Catholic Univ. of America Press, Washington 1956.

Hervada, J., Estructura y principios constitucionales del gobierno central de la Iglesia, Ius Canonicum 11 (1971) 11-55; ahora en J. HeRvadA, Vetera et nova. 
Cuestiones de derecho canónico y afines (1958-2004), $2^{\mathrm{a}}$ ed., Pamplona 2005, $187-233$.

IsIDORO DE SEVILla, Etimologías, ed. bilingüe, vol. I, BAC, Madrid 1982.

—, De ecclesiasticis officiis, en Corpus Christianorum, series latina, 113, Brepols, Turnholti, a cargo de Ch. M. Lawson.

Kantorowicz, E. H., The king's two bodies. A study in mediaeval political theology, Princeton University Press, Princeton NY 1957 (trad. esp.: Los dos cuerpos del rey: un estudio de teología politica medieval, Alianza, Madrid 1985).

LANDAU, P., Die Ursprünge des Amtsbegriff im klassischen kanonischen Recht. Eine quellengeschichtliche Untersuchung zum Amtsrecht und zum Archidiakonat im Hochmittelalter, en IDEM, Officium und libertas christiana, Verlag der Bayerischen Akademie der Wissenschaften, München 1991, 5-54 (estudio también publicado en IDEM, Europäische Rechsgeschichte und kanonisches Recht im Mittelalter, Wissenschaflicher Verlag Bachmann, Badenweiler 2013, 341-384).

Maccarrone, M., Vicarius Christi. Storia del titolo papale, Lateranum, Nova series, Romae 1953.

MichaUd-Quantin, P., «Universitas». Expressions du mouvement communautaire dans le moyen-age latin, Libraire philosophique J. Vrin, Paris 1970.

MONTAN, A., «Ministeria, munera, officia». I laici titolari di uffici e di ministeri (cann. 22, 230, 274). Precisazioni terminologiche, en GRUPPO ITALIANO DOCENTI DI DIRITTO CANONICO (a cura di), I laici nella ministerialità della Chiesa: XXVI Incontro di Studio, Glossa, Milano 2000, 99-134.

MoreIn, E. M., Officium ecclesiasticum et universitas personarum. Bestimmung des Rechsinstituts «Amt», LIT, Berlin 2006.

Orlandis, J., Historia de las instituciones de la Iglesia católica, Eunsa, Pamplona 2003.

QUINTANA-ORIVE, E., «Officium, munus, honor...»: precedentes romanos del término "funcionario" y de otras categorías jurídico-administrativas», Revista digital de Derecho Administrativo 16 (2016) 263-278 (http://dx.doi.org/10. 18601/21452946.n16.12.).

Souto, J. A., La noción canónica de oficio, Gómez, Pamplona 1971.

STICKLER, A. M., Historia del derecho canónico, en Sacramentum mundi, II, trad. esp., Barcelona 1972, 187-204.

—, La bipartición de la potestad eclesiástica en su perspectiva bistórica, Ius Canonicum 29 (1975) 45-74.

-, De potestatis sacrae natura et origine, Periodica de re morali, canonica, liturgica 71 (1982) 65-91. 


\section{ANTONIO VIANA}

Ulmann, W., The medieval papacy, St Thomas and beyond, original de 1960; ahora en IDEM, Law and jurisdiction in the Middle Ages, Variorum Reprints, London 1988, 1-31.

VIANA, A., Obispos titulares. Elementos de tradición canónica y regulación actual, Ius Canonicum 44 (2004) 515-537.

—, El problema de la participación de los laicos en la potestad de régimen. Dos vías de solución, Ius Canonicum 54 (2014) 603-638.

Villemin, L., Pouvoir d'ordre et pouvoir de juridiction: Histoire théologique de leur distinction, Les Éditions du Cerf, Paris 2003.

WERNZ, F. X., Ius decretalium ad usum praelectionum in scholis textus canonici sive iuris decretalium, II, Ius constitutionis Ecclesiae catholicae, Romae 1899.

Wolter, U., Amt und Officium in mittelalterlichen Quellen vom 13. bis 15. Fabrbundert, Zeitschrift der Savigny-Stiftung für Rechtsgeschichte. Kanonistische Abteilung 74 (1988) 246-280. 